\title{
Comparação nutricional e enzimática entre indivíduos saudáveis e fenilcetonúricos: revisão sistemática e metanálise
}

\author{
Nutritional and enzymatic comparison between healthy and phenylketonuric individuals: \\ systematic review and meta-analysis
}
Comparación nutricional y enzimática entre indivíduos sanos y fenilcetonúricos: revision sistemática y metanálisis

Lucas Cândido Gonçalves ${ }^{1}$, Marcos de Oliveira Cunha ${ }^{1}$, Gabriel de Oliveira Barbosa ${ }^{1}$, Thiago Alves Digues $^{1}$, Raphael Ladislau de Alcantara ${ }^{1}$, Xisto Sena Passos ${ }^{1}$, Milton Camplesi Junior ${ }^{1}$, Fábio Silvestre Ataídes ${ }^{1}$, Arisneide Kasue lkeda Rede ${ }^{1}$, Antonio Márcio Teodoro Cordeiro Silva1.

\section{RESUMO}

Objetivo: Este estudo objetivou avaliar as diferenças das médias de selênio, coenzima Q10 (CoQ10), status total antioxidante (STA), L-carnitina e glutationa peroxidase (GPx), comparando portadores de fenilcetonúria a indivíduos saudáveis, por meio de uma revisão sistemática e metanálise. Métodos: Para tal pesquisa foram selecionados 24 artigos, nas bases de dados PubMed e LILACS, 15 contribuíram com dados para as análises estatísticas, realizadas com o auxílio do software BioEstat ${ }^{\circledR}$ 5.3. Resultados: Todos os resultados referentes às concentrações séricas, demonstraram redução em fenilcetonúricos quando comparados com indivíduos saudáveis: selênio de 0,5 vez menor; $\mathrm{CoQ}_{10} \mathrm{com}$ média de 0,08 vez menor; STA com média das diferenças de 0,15 vez menor; L-carnitina livre com média igual 7,8 vezes menor e GPx com concentração 1 vez menor. Em todas as médias a significância foi evidente, com $p<0,0001$. Considerações finais: É explícito a necessidade de uma suplementação nutricional, como tratamento coadjuvante a dieta restritiva, com o objetivo de evitar danos às membranas celulares e ao material genético.

Palavras-chave: Fenilcetonúrias, Selênio, Ubiquinona, Acetilcarnitina, Estresse oxidativo.

\begin{abstract}
Objective: This study aimed to evaluate the differences in selenium averages, coenzyme Q10 (CoQ 10$)$, total antioxidant status (TAS), L-carnitine and glutathione peroxidase (GPx), comparing with phenylketonuria patients to healthy individuals, by means of a systematic review and meta-analysis. Methods: For this research, 24 articles were selected from the PubMed and LILACS databases, 15 contributed data to the statistical analyzes performed with the aid of BioEstat ${ }^{\circledR} 5.3$ software. Results: All results regarding serum concentrations showed a reduction in phenylketonurics when compared to healthy individuals: selenium 0.5 times lower; $\mathrm{CoQ}_{10}$ with an average of 0.08 times smaller; TAS with mean difference of 0.15 times smaller; Free L-carnitine with average 7.8 times lower and GPx with 1 times lower concentration. In all means the significance was evident, with $p<0.0001$. Final considerations: It is evident the need for nutritional supplementation, as an adjunctive treatment to restrictive diet, in order to avoid damage to cell membranes and genetic material.
\end{abstract}

Key words: Phenylketonuria, Selenium, Ubiquinone, Acetylcarnitine, Oxidative stress.

RESUMEN

Objetivo: Este estudio tuvo como objetivo evaluar las diferencias en los promedios de selenio, coenzima Q10 (CoQ10), estado antioxidante total (EAT), L-carnitina y glutatión peroxidasa (GPx) mediante la comparación de pacientes con fenilcetonuria con individuos sanos a través de una revisión sistemática y metanálisis. Métodos: Para esta investigación, se seleccionaron 24 artículos de las bases de datos PubMed y LILACS, 15 aportaron datos a los análisis estadísticos realizados con la ayuda del software BioEstat ${ }^{\circledR}$ 5.3. Resultados:

1Universidade Paulista, Goiânia-GO. *E-mail: lucascandidogoncalves46@gmail.com 
Todos los resultados con respecto a las concentraciones séricas mostraron una reducción en fenilcetonúricos en comparación con individuos sanos: selenio 0.5 veces menor; CoQ10 con un promedio de 0.08 veces menor; EAT con diferencia media de 0.15 veces menor; L-carnitina libre con un promedio de 7.8 veces menor y GPx con una concentración 1 veces menor. En todos los promedios, la significación fue evidente, con $\mathrm{p}<0,0001$. Consideraciones finales: $\mathrm{La}$ necesidad de suplementos nutricionales como tratamiento complementario a una dieta restrictiva es clara, para evitar daños a las membranas celulares y al material genético.

Palabras clave: Fenilcetonuria, Selenio, Ubiquinona, Acetilcarnitina, Estrés oxidativo.

\section{INTRODUÇÃO}

Fenilcetonúria (PKU; OMIM \#261600) é uma doença autossômica recessiva e sua prevalência mundial varia: na Europa 1:10.000 nascidos vivos, nos Estados Unidos da América (EUA) 1:15.000, na América Latina 1:25.000 a 1:50.000 recém-nascidos e no Brasil 1:25.000 nascidos vivos (NETO EV, et al. 2018; EICHINGER A, et al. 2018; ROSA RRPA, 2014).

Devido alterações no braço longo do cromossomo 12 (12q), há disfunção parcial ou total da enzima hepática fenilalanina hidroxilase (PHA; EC 1.14.16.1), que junto a tetrahidrobiopterina (BH4), exerce a função de acrescentar uma hidroxila no anel aromático da fenilalanina a transformando em tirosina (NETO EV, et al. 2018; ANDRADE F, et al. 2017).

Com a função enzimática comprometida, há por consequência, aumento de fenilalanina no plasma, posteriormente convertida em fenilpiruvato, fenilacetato e fenilactato. Estes metabólitos, possuem capacidade de atravessar a barreira hematoencefálica, atingindo o sistema nervoso central (SNC), provocando neurodegeneração e desmielinização dos axônios. Devido os danos associados ao SNC, fenilcetonúricos apresentam atraso cognitivo, convulsões e outros malefícios oriundos da toxicidade dos metabólitos. Com isso, portadores da doença aderem como tratamento a dieta restritiva, excluindo alimentos ricos em fenilalanina, substituindo estes alimentos por fórmulas de aminoácidos não fenilalanina, tornando por meio da ação, a diminuição da fenilalanina e seus metabólitos, consequentemente evitando os danos neurológicos associados aos mesmos, tornando possível o desenvolvimento cognitivo. Contudo, com a exclusão de alimentos ricos em fenilalanina, como: carnes, ovos, leite e derivados, há também exclusão de nutrientes essenciais para o organismo, principalmente para a capacidade antioxidante, excluindo nutrientes como: selênio, L-carnitina e coenzima Q10 (CoQ10) (SITTA A, et al. 2011; PREISSLER T, et al. 2015; KESHAVARZI F, et al. 2017).

A carência de selênio leva a redução funcional da Glutationa Peroxidase (GPx), a L-carnitina é de suma importância energética, principalmente em tecidos musculares e a CoQ ${ }_{10}$ tem propriedade antioxidante, além de ser de vital importância na cadeia respiratória, na produção de adenosina trifosfato (ATP) (SITTA A, et al. 2011; ANDRADE F, et al. 2017; KUMRU B, et al. 2019).

A adesão dietética de fenilcetonúricos com exclusão de alimentos ricos em fenilalanina culmina em carência de outros nutrientes essenciais para a capacidade antioxidante, causando assim um desequilíbrio entre a capacidade antioxidante e oxidante onde respectivamente há diminuição e aumento, resultando em estresse oxidativo. Com isso, o estresse oxidativo é ocasionado por meio do desequilíbrio entre a capacidade antioxidante e oxidante, provocando aumento de espécies reativas, estes causam danos às membranas das células, denominado lipoperoxidação. O mesmo ocorre com o ácido desoxirribonucleico (DNA) através do processo oxidativo (HALLIWELL B, 2006; PREISSLER T, et al. 2015).

Os danos elevam substâncias ou marcadores, estes podem ser encontrados no plasma, urina ou em outros materiais biológicos. Enfatizando o plasma, dois marcadores se destacam em indivíduos portadores de fenilcetonúria, sendo eles o malondialdeido (MDA), oriundo da lipoperoxidação e o 8-hidroxi-desoxigenase provindo da oxidação do DNA. Fenilcetonúricos tratados apresentam por meio de testes, falha no status antioxidante total (SAT), comprovado quando comparados indivíduos saudáveis com portadores da doença, que por ser de origem genética, não tem cura (KESHAVARZI F, et al. 2017). 
O perfil oxidante é importante para algumas funções do organismo, no entanto, com o desequilíbrio do perfil oxidante e antioxidante se estabelece o estresse oxidativo, ocasionado por radicais livres ou moléculas nocivas as células, em fenilcetonúricos o aumento de peroxido de hidrogênio associado com a carência de nutrientes essenciais para função enzimática, resultam em danos de diversas moléculas (ARTUCH R, et al., 2003).

Por outro lado, Radicais livres (RLs) não muito descritos em estudos onde o enfoque é fenilcetonúricos com estresse oxidativo, são átomos instáveis em sua última camada de valência, o átomo de hidrogênio é o mais comum, com apenas um elétron em sua orbita, outros exemplos são: radicais de hidroxila $\left(\mathrm{OH}^{-}\right)$e superóxido anion radical $\left(\mathrm{O}_{2}{ }^{-}\right)$. Todos $\mathrm{RLs}$ apresentam instabilidade e reagem com diversas moléculas, sendo danosos as células. Há também substâncias nocivas as células, estes são as denominadas espécies reativas de oxigênio (ROS), nesta classe temos o peroxido de hidrogênio $\left(\mathrm{H}_{2} \mathrm{O}_{2}\right)$, que em concentrações elevadas apresentam nocividade às membranas das células (HALLIWELL $B, 2006$ ).

Com a carência nutricional o perfil enzimático em fenilcetonúricos é comprometido. O status antioxidante abrange uma diversidade de enzimas, além da GPx que elimina o excesso de peroxido de hidrogênio $\left(\mathrm{H}_{2} \mathrm{O}_{2}\right)$, outra enzima responsável por decompor $\mathrm{H}_{2} \mathrm{O}_{2}$ é a catalase (CAT), realizando a seguinte ação: $2 \mathrm{H}_{2} \mathrm{O}_{2}$ decomposto em duas moléculas de hidrogênio mais uma de oxigênio $\left(2 \mathrm{H}_{2} \mathrm{O}+\mathrm{O}_{2}\right)$ (GLORIEUX C; CALDERON PB, 2017; ZALEWSKA-ZIOB M, et al. 2019). Não menos importante, a enzima superóxido dismutase (SOD) como o próprio nome diz, promove a catalisação do radical superóxido anion, o transformando em oxigênio mais peroxido de hidrogênio $\left(\mathrm{O}_{2}+\mathrm{H}_{2} \mathrm{O}_{2}\right)$ (GARETH SA, et al. 2019).

Com isso, é explicito a importância destas enzimas para capacidade antioxidante. Considerando a composição e cofatores destas enzimas, é importante visar uma dieta composta por tais nutrientes. $\mathrm{Na}$ estruturação da GPx é encontrado o selênio (Se) e na SOD o zinco e o cobre ( $\mathrm{Zn}$, $\mathrm{Cu}$ ). Por tanto, é um perfil segregado em enzimático e não enzimático, ambos com diminuição em fenilcetonúricos (BARBOSA KBF, et al. 2010).

O selênio é um importante micronutriente e pode ser absorvido pelo intestino delgado e posteriormente distribuído em vários tecidos do organismo, exercendo importantes funções biológicas, principalmente na regulação da síntese de selenoproteinas. No organismo, as selenoproteinas exerce derivadas funções e estão distribuídas pelos diversos sistemas. lodotironina desiodinases (IDD), tioredoxina redutase (TrxR) e glutationa peroxidase (GPx), são algumas das selenoproteinas humanas, onde o selênio é essencial para a atividade delas. Desta forma, o selênio desempenha importante papel como cofator de enzimas envolvidas tanto na síntese ou produção hormonal, como por exemplo hormônios tireoidianos, quanto na eliminação de peroxido de hidrogênio, através da glutationa peroxidase e eliminação de espécies reativas de oxigênio quando associado a enzima tioredoxina redutase, demonstrando assim, extrema importância antioxidante no meio extracelular e intracelular (WANG N, et al. 2017).

A L-carnitina fornecida de forma exógena através da alimentação ou sintetizada no organismo, sendo esta considerada endógena, exerce importante função no transporte de ácidos graxos de cadeia longa, estes são ativados no citoplasma das células, formando acil-CoA que, por intermédio da carnitina é transportado o acilo para o meio interno da mitocôndria, onde ocorrerá a $\beta$-oxidação e posteriormente a produção de energia celular (PEKALA J, et al. 2011).

Com isso, a L-carnitina está envolvida com o bom prognóstico em doenças cardiovasculares, com redução de lipídeos extracelulares e aumento de adenosina trifosfato (ATP), sendo de essencial importância principalmente ao miocárdio (PEKALA J, et al. 2011).

A coenzima Q10 ou Ubiquinona, está envolvida com o transporte de elétrons na cadeia respiratória, onde realiza a passagem de elétrons provindos das coenzimas: dinucleotideo nicotinamida e adenina (NADH) e dinucleotideo flavina e adenina (FADH2), dos complexos I e II, respectivamente NADH ubiquinona redutase e Succinato: ubiquinona redutase, para o complexo III (Ubiquinol-citocormo $\mathrm{C}$ redutase), processo essencial para fosforilação oxidativa, sabendo que a fosforilação ocorre por meio da energia dos elétrons de hidrogênios presentes entre as membranas interna e externa da mitocôndria, que ao retornar através da ATP sintetase, 
tem ação energética, essencial para a síntese de ATP, através da ligação de um fosfato inorgânico (Pi) à molécula de adenosina difosfato (ADP). Além disso, a $\mathrm{CoQ}_{10}$ quando na sua forma reduzida, denominada Ubiquinol (CoQ10H2), desempenha papel antioxidante, protegendo membranas plasmáticas e lipoproteínas contra os radicais livres, por oxidação induzida. Dentre as várias funções benéficas ao sistema metabólico, a CoQ10 realiza sinalização celular e expressão gênica (HARGREAVES IP, et al., 2007).

Diante disso, o objetivo deste estudo foi comparar níveis séricos de selênio, CoQ10, L-carnitina e atividade de GPx em portadores de fenilcetonúria, comparando-os a indivíduos saudáveis, relacionar carência de CoQ 10 e L-carnitina Livre com a produção comprometida de adenosina trifosfato (ATP) e estabelecer se há significância na diferença das médias séricas dos micronutrientes em questão, entre fenilcetonúricos e indivíduos saudáveis, por meio de revisão sistemática com metanálise.

\section{MÉTODOS}

Este estudo constituiu-se de revisão sistemática e metanálise com adoção do aspecto descritivo. Segundo Baena CP, (2014), revisão sistemática caracteriza-se como delineamento de trabalho com condução e abordagem sistemática, de descrição objetiva da evidência sintetizada, por outro lado a metanálise é caracterizada pelo método estatístico de análise de evidência reunida de forma sistematicamente.

Foram selecionados artigos referentes à comparação do perfil antioxidante enzimático e não enzimático entre fenilcetonúricos e indivíduos saudáveis para revisão sistemática e metanálise, da mesma forma artigos que abordavam vias metabólicas e estresse oxidativo para enriquecer o aspecto descritivo. Após consulta aos Descritores em Ciências da Saúde (DeCS) e Medical Subject Headings (MeSH), identificaram-se os descritores: fenilcetonúrias, selênio, ubiquinona, acetilcarnitina e estresse oxidativo. Foram então acessados, no período de janeiro de 2017 a junho de 2019, no site National Center for Biotechnology Information (NCBI) na base de dados Medical Literature Analysis and Retrieval System Online (MEDLINE), no site Literatura Latino-Americana e do Caribe em Ciências da Saúde (LILACS) e na base de dados ScienceDirect. Para pesquisa avançada os operadores booleanos "AND", "OR" e "NOT" foram utilizados. Foram identificadas 61 referências e excluídas 2 repetições e 19 publicações que não eram relacionadas ao tema, resultando em 40 referências utilizadas neste artigo onde 15 contribuíram com dados para as análises estatísticas. Para metanálise foram considerados artigos entre o intervalo de 1990 a 2019 e para o aspecto descritivo considerados artigos publicados entre 2004 e 2019. Os critérios para inclusão foram: artigos originais, artigos que continham dados estatísticos e informações importantes para o aspecto descritivo, artigos que descreviam a associação da carência nutricional com o estresse oxidativo em fenilcetonúricos, artigos publicados nos idiomas inglês, português e espanhol. As exclusões apresentavam uma das seguintes características: livros, dissertações de mestrado e teses de doutorado e artigos que não apresentavam os dados relativos ao tema. O modelo de fluxograma adotado foi o encontrado no PRISMA, 2009, destacado nos trabalhos de Liberati A, et al., (2009) e Moher D, et al. (2015), adaptado neste estudo (Figura 1).

Após a seleção dos estudos, de acordo com os critérios de inclusão e exclusão, foram extraídos e tabulados os dados de 15 artigos, referentes as seguintes análises: selênio (oito), CoQ10 (sete), STA (cinco), $\mathrm{L}$-carnitina (quatro), GPx (sete). As unidades de medida referentes ao selênio foram convertidas de $\mu \mathrm{g} / \mathrm{L}$ para $\mu \mathrm{mol} / \mathrm{L}$.

Outras conversões necessárias foram realizadas a fim de se obter um resultado assertivo referente a diferença das médias. Com o auxílio do software BioEstat ${ }^{\circledR}$ 5.3, foi realizado o teste estatístico de efeito fixo para dados contínuos, com a finalidade de determinar a diferença das médias entre fenilcetonúricos e indivíduos saudáveis, através do software também foram confeccionados os gráficos. Todas as comparações são referentes aos dados de dosagens séricas, a priori extraídos dos estudos selecionados. Assim, foram comparadas as médias de selênio nos grupos caso $(n=287)$ e controle $(n=276)$; CoQ 10 nos grupos caso $(n=201)$ e controle $(n=169)$; STA nos grupos caso $(n=116)$ e controle $(n=98)$; L-carnitina nos grupos caso $(n=174)$ e controle $(n=189)$ e GPx nos grupos caso $(n=281)$ e controle $(n=254)$. 
Figura 1 - Fluxograma: processo seletivo de artigos utilizados na revisão sistemática e metanálise.
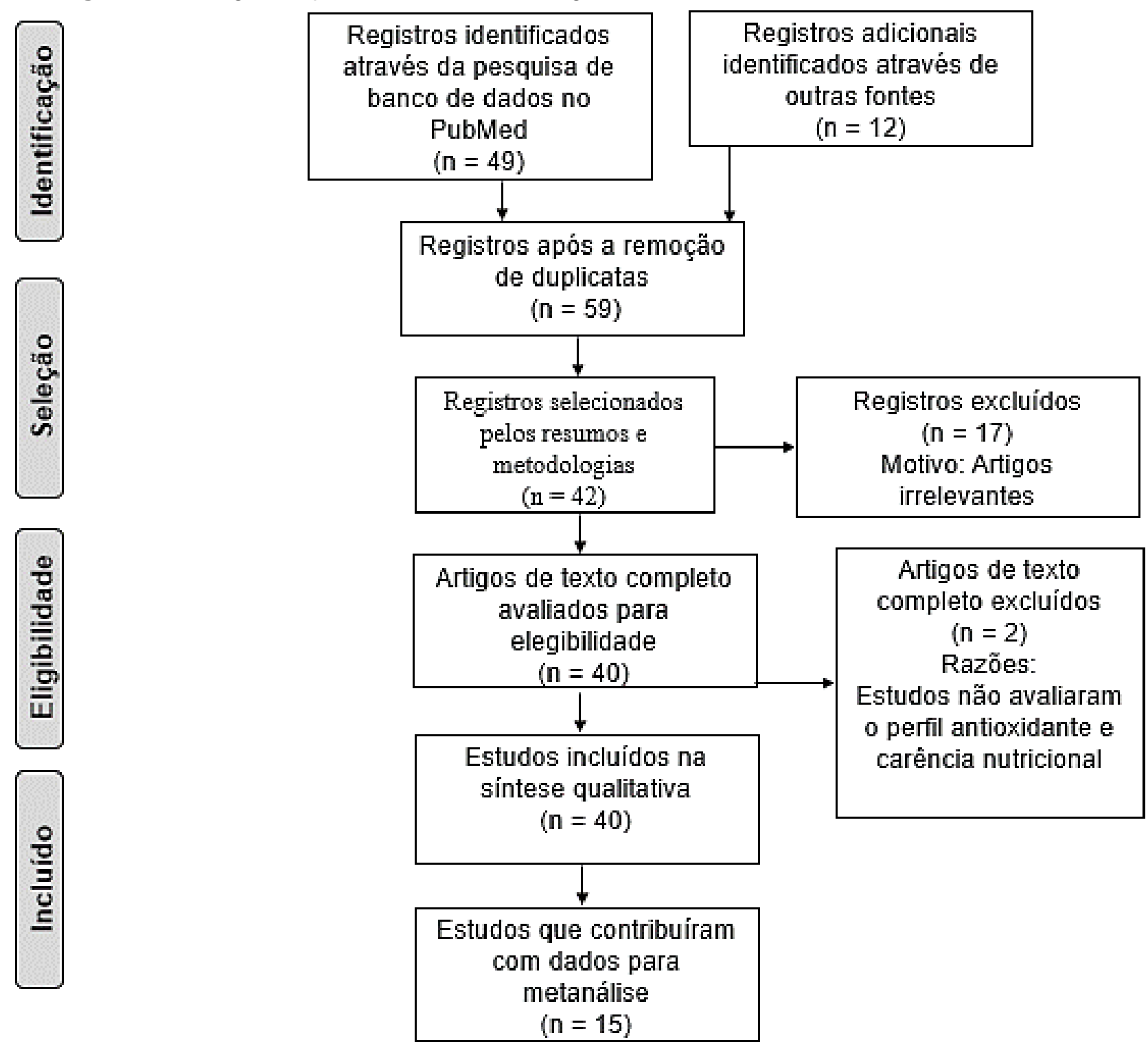

Fonte: Gonçalves LC, et al., 2019. Adaptado de Liberati A, et al., 2009.

\section{RESULTADOS E DISCUSSÃO}

Os resultados demonstraram diferenças significativas em todos os perfis, de acordo com o teste estatístico aplicado. Quando observado o gráfico referente ao selênio, em $25 \%$ dos estudos segregados a priori, não demonstraram significância, estes estudos respectivamente Artuch R, et al., (2003) e Sierra C, et al., (1988). Em contrapartida com $75 \%$ de estudos com significância para metanálise em questão. Com isso, o selênio apresentou média das diferenças de 0,50 (IC95\%=0,49-0,52; $p<0,0001)$. Indicando que em indivíduos portadores de fenilcetonúria, o nível sérico de selênio está em média, $0,50 \mu \mathrm{mol} / \mathrm{L}$ ou $39 \mu \mathrm{g} / \mathrm{L}$ menor, quando comparados a indivíduos saudáveis (Figura 2).

$40 \%$ das pesquisas referentes a $\mathrm{CoQ}_{10}$, demonstraram insignificância entre os níveis séricos de casos e controles, onde houve uma maior contraposição no estudo de Mikoluc B, et al., (2012). Os resultados contidos no estudo de Kumru B, et al, (2018), não demonstraram relevância, divergindo com a pesquisa de mesma autoria, onde Kumru B, et al., (2019) com maior peso de acordo com o gráfico, confirmou relevância. Através do teste a $\mathrm{CoQ}_{10}$ apresentou diminuição com média das diferenças de $0,079(\mathrm{IC} 95 \%=0,052=0,105 ; p<0,0001)$. A média das diferenças indica uma diminuição de $\mathrm{CoQ}_{10}$ em fenilcetonúricos com média igual a $0,079 \mu \mathrm{mol} / \mathrm{L}$ ou $68 \mu \mathrm{g} / \mathrm{L}$ menor, quando comparados com indivíduos saudáveis (Figura 3). 
Figura 2 - Forest Plot: Médias Séricas de Selênio ( $\mu \mathrm{mol} / \mathrm{L})$ segundo estudos.

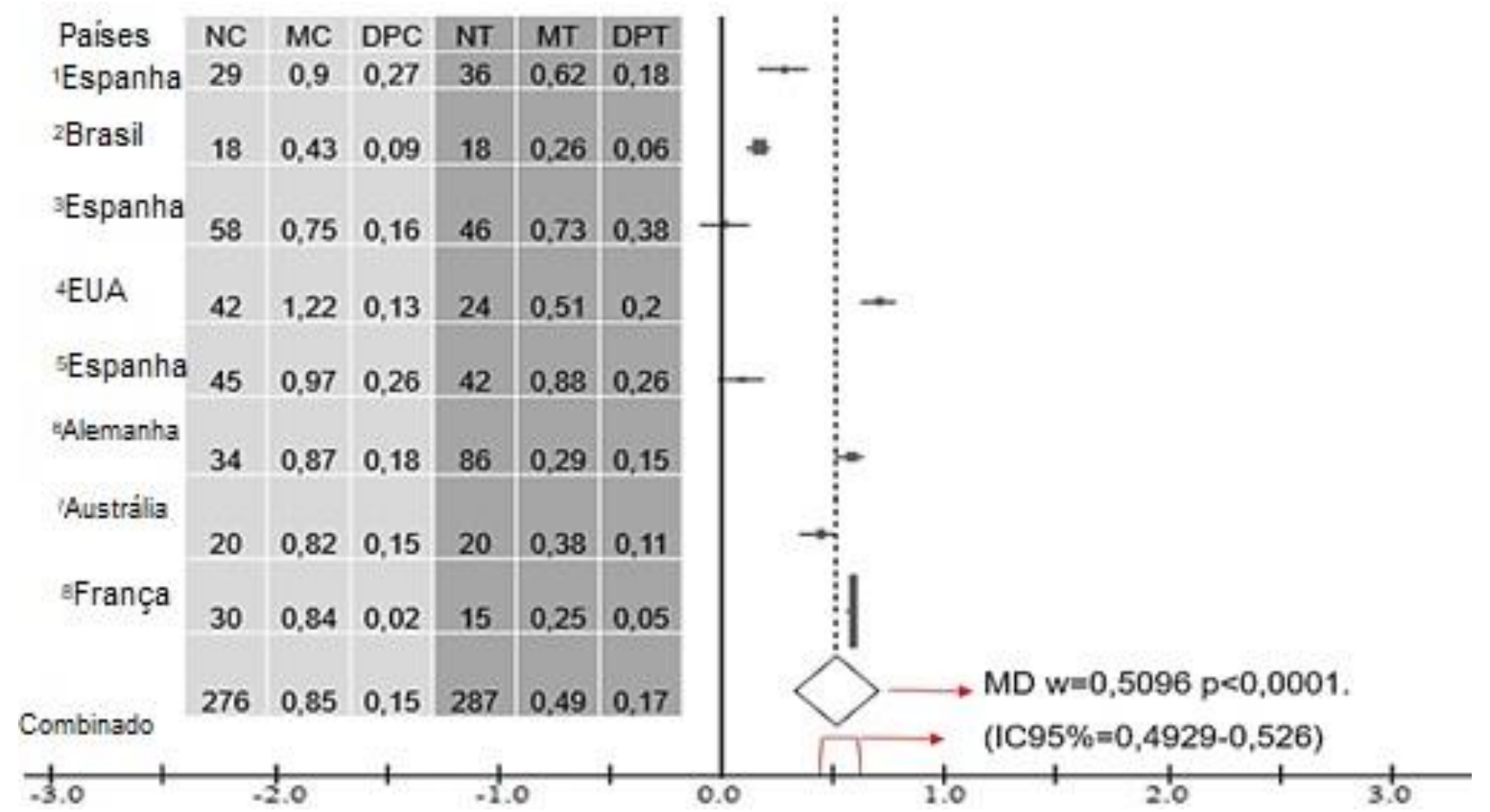

Legenda: O números se referem a cada autor e ano do estudo: ${ }^{1}$ Gassió $R$, et al., 2008; ${ }^{2}$ Sitta $A$, et al., 2011; ${ }^{3}$ Artuch R, et al., 2003; ${ }^{4}$ Van Bakel MME, et al., 2000; ${ }^{5}$ Sierra C, et al., 1998; ${ }^{6}$ Jochum F, et al., $1999 ;{ }^{7}$ Reilly C, et al., 1990; ${ }^{8}$ Wilke BC, et al, 1992; Gráfico Forest Plot: Dados: Apresentando número controle (NC), média controle (MC), desvio padrão controle (DPC), número teste (NT), média teste (MT), desvio padrão teste (DPT). Resultados: MD w=0,5096 (IC95\%=0,4929 a 0.5261 p<0,0001). Fonte: Gonçalves LC, et al., 2019.

Figura 3 - Forest Plot: Médias Séricas de Coenzima Q10 ( $\mu \mathrm{mol} / \mathrm{L})$ segundo estudos.

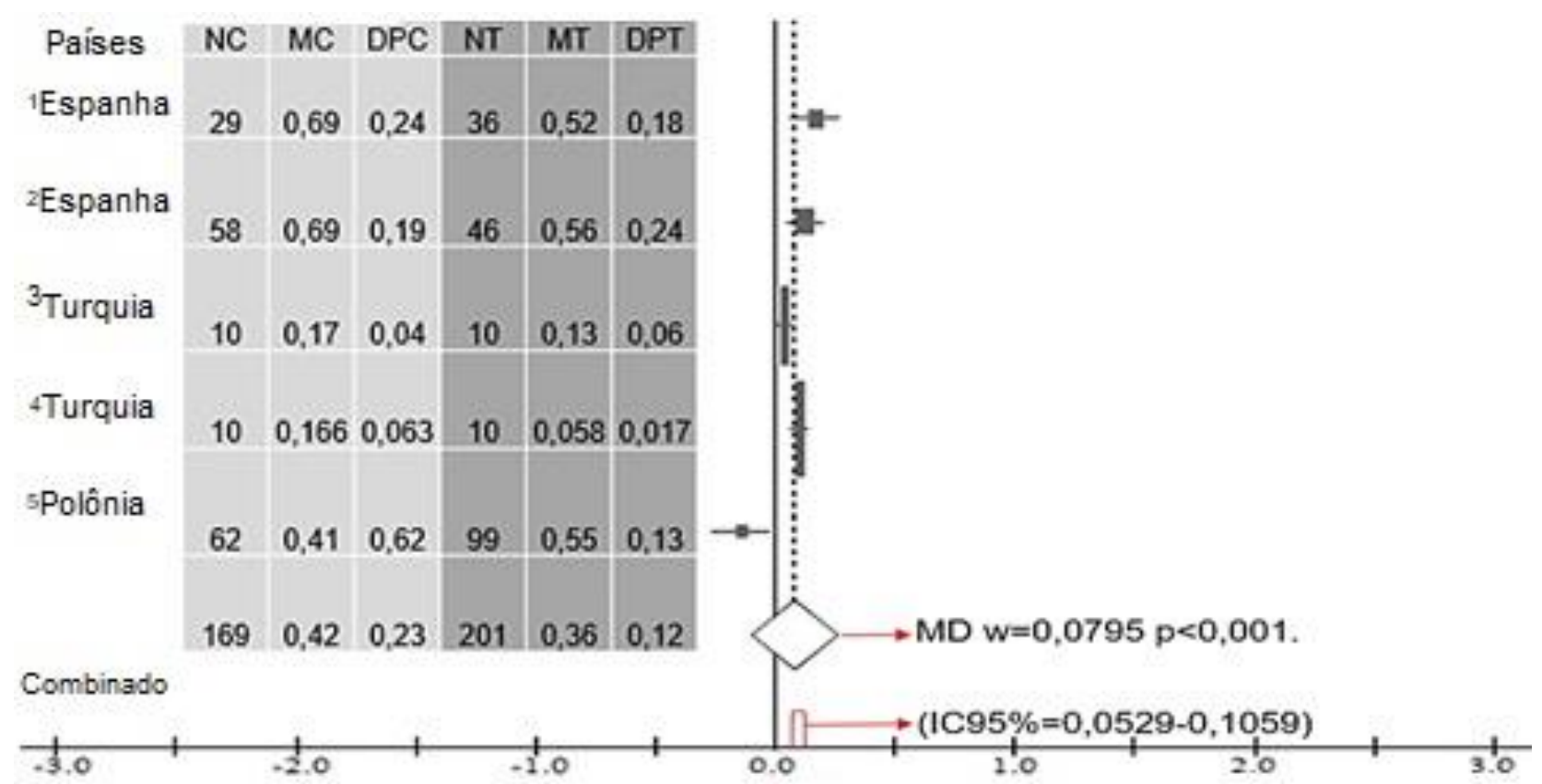

Legenda: O números se referem a cada autor e ano do estudo: ${ }^{1} G$ assió $R$, et al., 2008; ${ }^{2}$ Artuch $R$, et al., 2003; ${ }^{3}$ Kumru B, et al., 2018; ${ }^{4}$ Kumru B, et al., 2019; ${ }^{5}$ Mikoluc B, et al., 2012. Gráfico Forest Plot: Dados: Apresentando número controle (NC), média controle (MC), desvio padrão controle (DPC), número teste (NT), média teste (MT), desvio padrão teste (DPT). Resultados: MD w=0,0795 (IC95\%=0,0529 a 0,1059 p<0,0001). Fonte: Gonçalves LC, et al., 2019. 
Os estudos referentes ao status total antioxidante, demonstrou maior porcentagem de irrelevância de níveis séricos entre grupos casos e controles para esta metanálise, onde apenas a pesquisa de Ekin S, et al., (2018) referente a apenas $20 \%$ dos estudos selecionados, demonstraram grande diferença entre as medias séricas casos/controle. No entanto, o estudo em questão demonstrou maior peso, interferindo crucialmente no resultado final, onde o status total antioxidante (STA) teve a média das diferenças igual a 0,15 (IC95\%=0,12-0,18; $p<0,0001)$, evidenciando que em fenilcetonúricos o status total antioxidante está em

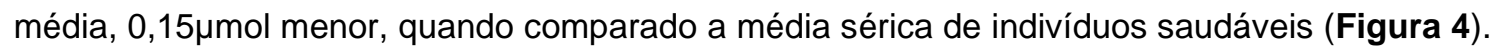

Apenas $28,5 \%$ dos estudos referentes as comparações séricas de L-carnitina livre demonstraram-se sem relevância para a pesquisa em questão. Kumru B, et al., (2018) e Kumru B, et al., (2019), em seus dois estudos destacaram a significância entre as diferenças séricas $\mathrm{O}$ estudo de Bohles $\mathrm{H}$, et al., (1990) foi o estudo com maior peso de acordo com o gráfico, logo após Weigel C, et al., (2008). Com isso, os resultados referentes a L-carnitina livre apontaram uma diferença das médias de 7.8 (IC95\%=6,50-9,28; $p<0.0001$ ), evidenciando que em indivíduos portadores de fenilcetonúria, níveis séricos de L-carnitina estão em média aproximada a $8 \mu \mathrm{mol} / \mathrm{L}$ a menos, quando comparado a média sérica de indivíduos saudáveis (Figura 5).

Com $28,5 \%$ de estudos sem resultados relevantes entre as médias de GPx para a pesquisa em questão, a enzima demonstrou diferença significativa, com médias das diferenças de 0,9 (IC95\%=0,8084-1,1702; $\mathrm{p}<0,0001$ ), evidenciando que em fenilcetonúricos, a GPx está aproximadamente $1 \mathrm{U} / \mathrm{g}$ de Hemoglobina menor quando comparados a indivíduos saudáveis. Gassió R, et al., (2008) e Artuch R, et al., (2003) foram os estudos com resultados sem significância de acordo com o disposto no gráfico, onde o estudo com maior peso foi o de Ekin S, et al., (2018) (Figura 6).

Figura 4 - Forest Plot: Médias Séricas de Status total antioxidante $(\mu \mathrm{mol} / \mathrm{L})$ segundo estudos.

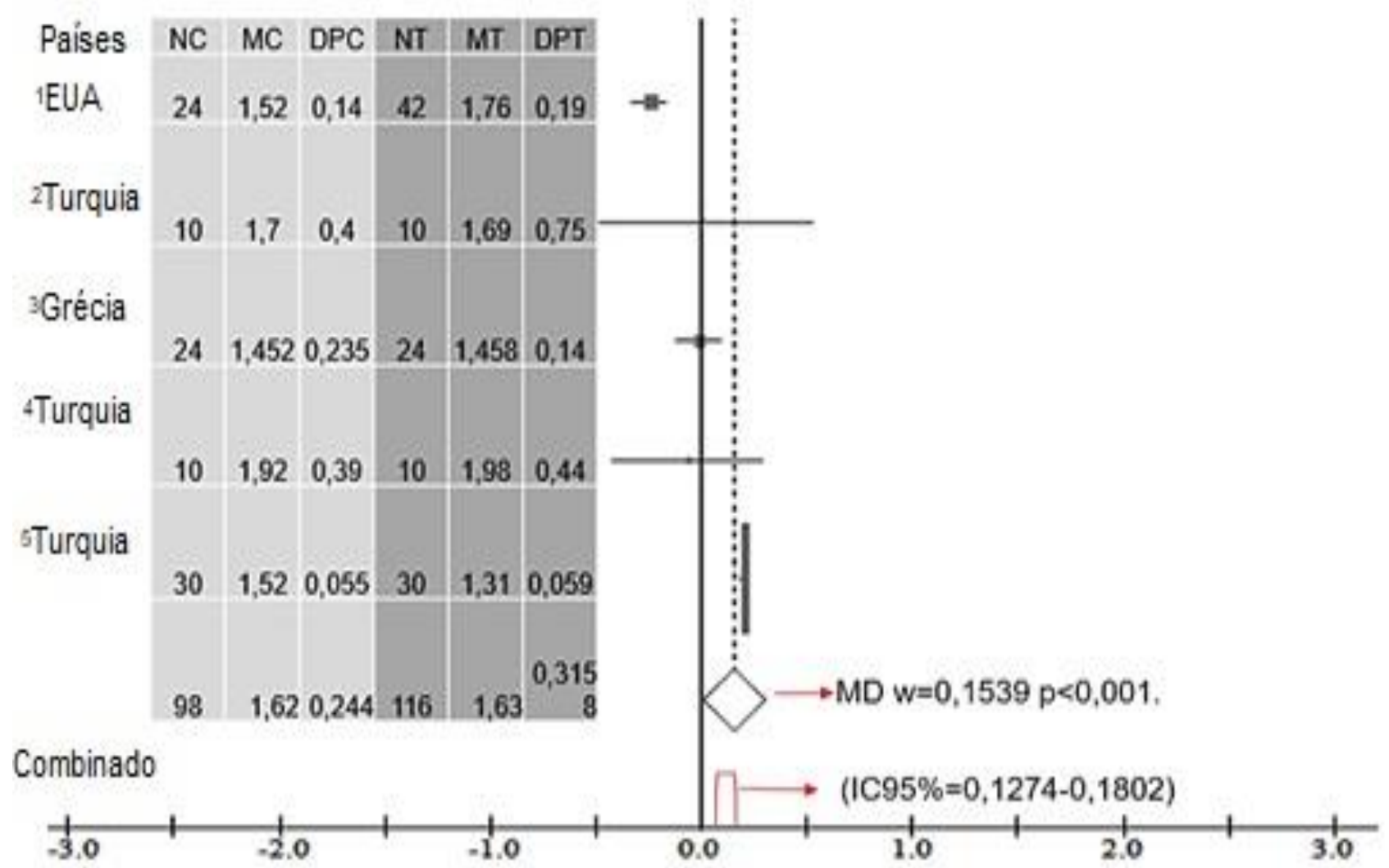

Legenda: $O$ números se referem a cada autor e ano do estudo: ${ }^{1}$ Van Bakel MME, et al., 2000; ${ }^{2} \mathrm{Kumru} B$, et al., 2018; ${ }^{3}$ Schulpis KH, et al., 2004; ${ }^{4}$ Kumru B, et al., 2019; ${ }^{5}$ Ekin S, et al., 2018. Gráfico Forest Plot: Dados: Apresentando número controle (NC), média controle (MC), desvio padrão controle (DPC), número teste (NT), média teste (MT), desvio padrão teste (DPT). Resultados: MD w=0,1539 (IC95\%=0,1274 a 0,1802 p<0,0001). Fonte: Gonçalves LC, et al., 2019. 
Figura 5 - Forest Plot: Médias Séricas de Carnitina Livre ( $\mu \mathrm{mol} / \mathrm{L})$ segundo estudos.

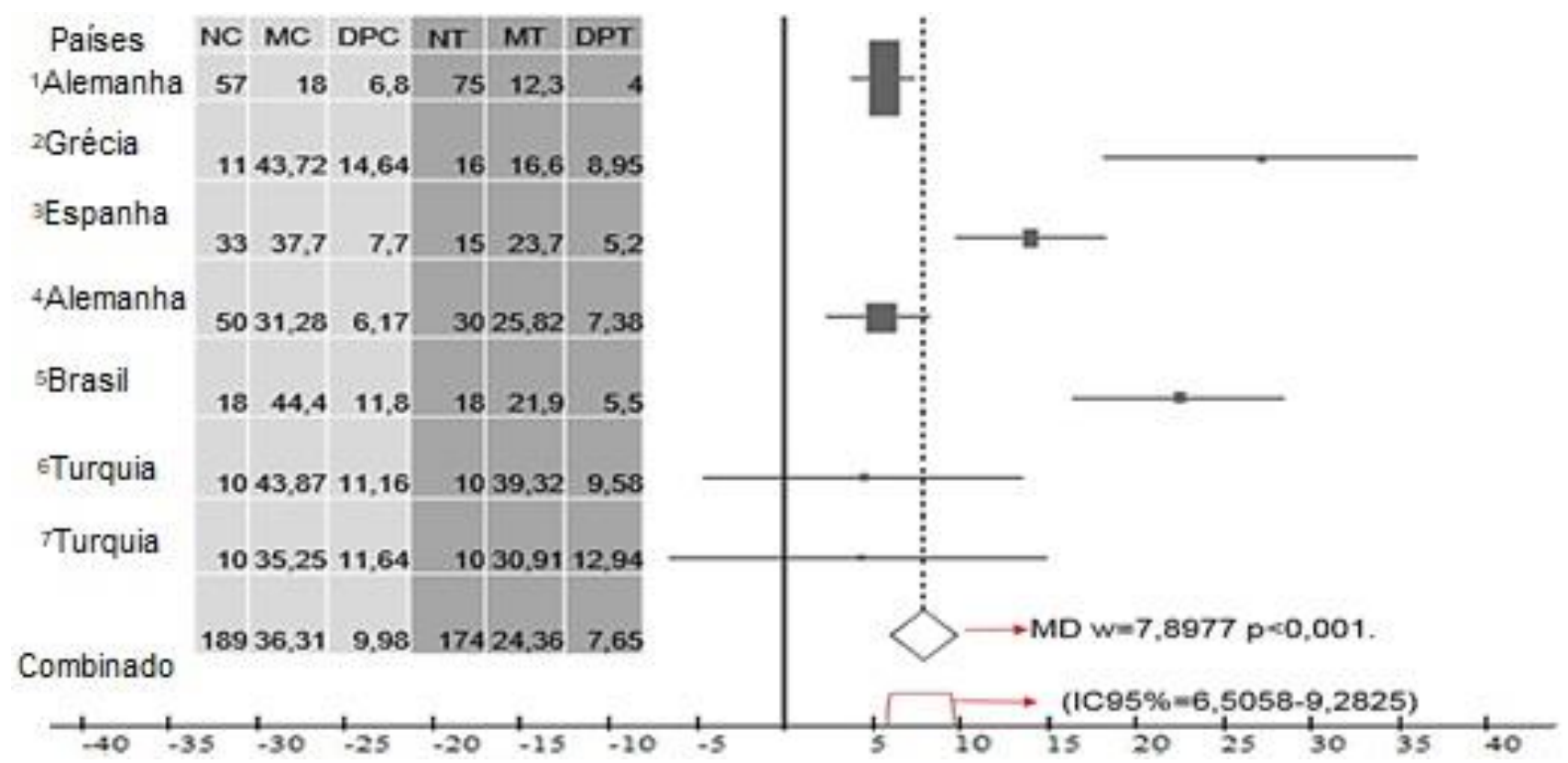

Legenda: $O$ números se referem a cada autor e ano do estudo: ${ }^{1}$ Bohles $\mathrm{H}$, et al., $1990{ }^{2}$ Schulpis $\mathrm{KH}$, et al., 2004; ${ }^{3}$ Vilaseca MA, et al., $1993{ }^{4}$ Weigel C, et al., 2008; ${ }^{5}$ Sitta A, et al., 2011; ${ }^{6}$ Kumru B, et al., 2018; ${ }^{7}$ Kumru B, et al., 2019. Gráfico Forest Plot: Dados: Apresentando número controle (NC), média controle (MC), desvio padrão controle (DPC), número teste (NT), média teste (MT), desvio padrão teste (DPT). Resultados: MD $\mathrm{W}=7,8977(\mathrm{IC} 95 \%=6,5058$ a $9,2825 \mathrm{p}<0,0001)$.

Fonte: Gonçalves LC, et al., 2019.

Figura 6 - Forest Plot: Médias Séricas de Glutationa Peroxidase $(\mathrm{U} / \mathrm{g} \mathrm{Hb})$ segundo estudos.

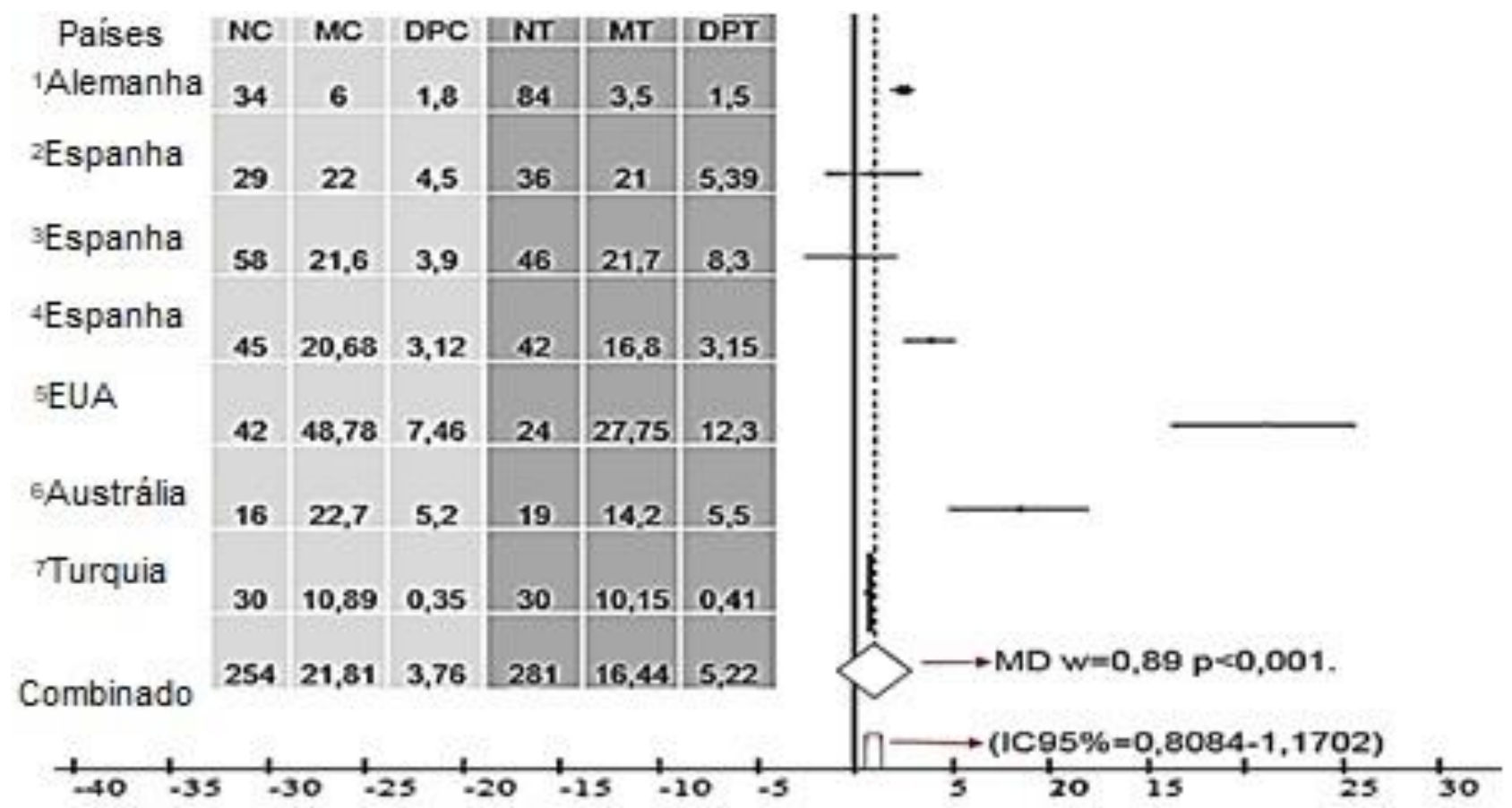

Legenda: O números se referem a cada autor e ano do estudo:1 Jochum $F$, et al., 1999; ${ }^{2}$ Gassió R, et al., 2008; ${ }^{3}$ Artuch R,et al., $2003{ }^{4}$ Sierra C, et al., 1998; ${ }^{5}$ Van Bakel MME, et al., 2000; ${ }^{6}$ Reilly C, et al., 1990; ${ }^{7}$ Ekin $\mathrm{S}$, et al., 2018. Gráfico Forest Plot: Dados: Apresentando número controle (NC), média controle (MC), desvio padrão controle (DPC), número teste (NT), média teste (MT), desvio padrão teste (DPT). Resultados: MD $\mathrm{W}=0,89(\mathrm{IC} 95 \%=0,8084$ a $1,1702 \mathrm{p}<0,0001)$.

Fonte: Gonçalves LC, et al., 2019. 
As diferenças das médias séricas, entre grupos controle e caso, são consequências da dieta restrita a alimentos que contém fenilalanina. De acordo com Kumru B, et al. (2019), a redução da enzima GPx é uma resposta a carência de selênio na dieta de fenilcetonúricos, que ao excluírem alimentos ricos em fenilalanina, também excluem este importante nutriente, o qual exerce importante papel como cofator da GPx. Durebex $C V$, et al. (2017) numa pesquisa, associaram danos ocasionados às membranas das células à redução de GPx. A redução de GPx desencadeia o estresse oxidativo com o aumento de espécies reativas de oxigênio (ERO), consequentemente, causando danos às membranas e ao material genético. A depleção da GPx contrasta com o aumento de MDA, consequência da lipoperoxidação associada ao aumento de peroxido de hidrogênio $\left(\mathrm{H}_{2} \mathrm{O}_{2}\right)$, uma vez que a ação enzimática sobre tal substância, promove a liberação de duas moléculas de água $\left(2 \mathrm{H}_{2} \mathrm{O}\right)$, evitando assim danos à membrana plasmática. Com isso, é evidente os efeitos maléficos da carência nutricional, onde os níveis séricos de selênio quando reduzido, leva a depleção funcional de GPx e consequentemente a lipoperoxidação causada pelo $\mathrm{H}_{2} \mathrm{O}_{2}$.

Segundo Halliwell B, (2006), o metabolismo no sistema nervoso central (SNC) gera muito peroxido de hidrogênio, provindo não somente da ação de superóxido dismutase (SOD), mas também de outras enzimas, como as flavoproteínas localizadas nas membranas externas das mitocôndrias dos neurônios e células da glia, demonstrando a evidente vulnerabilidade do SNC diante do peroxido de hidrogênio, levando em consideração não somente a membrana celular, más também bainha de mielina, responsável por proteger os axônios.

O MDA, marcador de lipoperoxidação, também é encontrado em indivíduos saudáveis. No estudo de Keshavarzi F, (2017), a média do nível sérico de MDA no grupo controle foi $12,7 \mu \mathrm{mol} / \mathrm{L}$ com desvio padrão de $2,2 \mu \mathrm{mol} / \mathrm{L}(12,7 \pm 2,2)$, porem no grupo caso o nível foi $20,6 \mu \mathrm{mol} / \mathrm{L}$ com desvio padrão de $0,9 \mu \mathrm{mol} / \mathrm{L}$ $(20,6 \pm 09)$, evidenciando lipoperoxidação com maior grau em portadores da doença. Outro marcador elevado em portadores da doença é o 8didroxi-desoxigenase $(8 \mathrm{OHdG})$, proveniente da oxidação do material genético.

As médias de selênio e GPx em fenilcetonúricos, respectivamente 0,5 e 0,9, evidenciaram relação entre os níveis, levando em consideração a necessidade de selênio para função da GPx. Da mesma forma, segundo Kumru B, et al. (2018), a redução dos níveis séricos de $\mathrm{CoQ}_{10}$ e L-carnitina podem ser explicados pela carência nutricional. A diminuição de $\mathrm{CoQ}_{10}$ e L-carnitina tem por consequência a depleção da capacidade antioxidante em fenilcetonúricos com boa adesão dietética (KUMRU B, et al. 2019). Os níveis séricos de $\mathrm{CoQ}_{10}$ segundo Castillo $M$, et al., (1988), tem sua síntese comprometida pelo aumento de fenilalanina, ocorrendo o mesmo com os níveis séricos de GPx de acordo com o estudo de Hagen MEK, et al., (2002). Com isso, a CoQ 10 se torna alvo, com depleção ocasionada pela exclusão de alimentos e hiperfenilalanemia, que mesmo controlada, a concentração sérica é elevada em portadores da doença com boa adesão ao tratamento quando comparados a indivíduos saudáveis, ou seja, seguindo ou não a dieta, a carência e os efeitos maléficos se farão presentes. Levando em consideração as funções da $\mathrm{CoQ}_{10}$ no organismo, Hargreaves IP, (2007) em seu estudo, salientou a contribuição do déficit de CoQ10 nos processos fisiopatológicos, favorecendo-os.

Com a redução de L-carnitina, há aumento sérico de lipídeos, pois este nutriente é de suma importância no transporte de ácidos graxos de cadeia longa até às mitocôndrias, onde ocorre a $\beta$-oxidação, cujo objetivo é a produção de ATP. Com isso, fenilcetonúricos são mais susceptíveis às doenças cardiovasculares e neurológicas, como por exemplo: aterosclerose e acidente vascular cerebral (AVC), respectivamente. É comprovado após suplementação com L-carnitina, a beneficência e o melhor prognóstico em indivíduos com casos de cardiomiopatias. Isso se dá pela redução dos ácidos graxos e consequentemente redução de colesterol total. Com isso, a carnitina demonstrou impacto benéfico em casos fisiológicos associados, como parada cardiopulmonar, infarto coronariano, lesão miocárdica toxica e diabetes (WANG ZY, et al. 2018).

A depleção do nível sérico de L-carnitina em portadores de fenilcetonúria, demonstra a maior suscetibilidade deles em desenvolverem doenças cardiovasculares, neurológicas e diabetes. Considerando o tema proposto no trabalho em questão, fenilcetonúricos apresentaram elevada concentração de ácidos graxos de cadeia longa no meio extracelular, quando comparados com indivíduos saudáveis, e como consequência lipoperoxidação agravada, considerando a depleção de GPx e consequentemente aumento de 
peroxido de hidrogênio. A produção de ATP comprometida se acentua com a carência de CoQ10, considerando que ela é de grande importância no transporte de elétrons na cadeia respiratória, via responsável pela maior produção de energia celular. A coenzima Q10 quando na sua forma reduzida, denominada Ubiquinol, desempenha importante função antioxidante, protegendo as membranas e lipoproteínas, contra as espécies reativas de oxigênio, com isso, a suscetibilidade a lipoperoxidação é aumentada, provindo da baixa defesa contra as espécies reativas. No presente estudo, foram demonstradas depleções das médias de $\mathrm{CoQ}_{10}$ e L-carnitina em portadores da doença, respectivamente 0,07 e 7,8. A Lcarnitina está presente principalmente em produtos cárneos, leite e derivados (PREISSLER T, et al. 2015), com isso, é evidente que a exclusão destes alimentos, tem por consequência a carência de L-carnitina.

O status total antioxidante (STA) reduzido em portadores da doença é o reflexo da carência nutricional. As diminuições dos níveis séricos de L-carnitina, selênio, $\mathrm{CoQ}_{10}$ e a atividade comprometida da Glutationa Peroxidase, demonstra ação devastadora às células, tecidos e órgãos. Cada micronutriente na sua depleção resulta em malefícios isolados e simultaneamente exercem efeitos sinérgicos entre si. Esta afirmação pode ser comprovada através do resultado obtido referente ao status total antioxidante com média igual a 0,15 $(p<0,0001)$. O status total antioxidante leva em consideração todo o conjunto de enzimas e nutrientes, não somente as carências e enzimas destacadas neste trabalho. Outras enzimas a serem evidenciadas são: superóxido dismutase (SOD) e catalase (CAT), onde estudos comprovam a depleção das mesmas (ARTUCH R, et al. 2003; GASSIÓ R, et al. 2008).

\section{CONSIDERAÇÕES FINAIS}

A dieta restritiva é de extrema importância para o desenvolvimento neuroanatômico e neurofisiológico em fenilcetonúricos. No entanto, o estresse oxidativo se faz presente exacerbadamente nestes indivíduos, consequência da carência nutricional proporcionada pela dieta, que ocasiona diminuição da capacidade antioxidante enzimática e celular. Os níveis séricos de selênio, L-carnitina e CoQ10, demonstraram resultados significativamente menores em portadores da doença, quando comparados a indivíduos saudáveis. Da mesma forma a GPx, evidenciando a necessidade de tratamento coadjuvante, com a suplementação nutricional. Todos os perfis analisados nesta metanálise demonstraram diferenças significantes. Considerando as funções dos nutrientes, é nítido o comprometimento do metabolismo em fenilcetonúricos, com redução do STA, onde os danos ocasionados pela depleção enzimática são intensificados com a diminuição de energia celular, sabendo que para regeneração celular é necessário ATP.

\section{REFERÊNCIAS}

1. ANDRADE F, et al. Influence of phenylketonuria's diet on dimethylated arginines and methylation cycle. Medicine, 2017; 1 -7.

2. ARTUCH R, et al. A longitudinal study of antioxidant status in phenylketonuric patients. Clinical Biochemistry, 2003; 37(3): 198-203.

3. BAENA CP, Meta-Analysis and Systematic Review: Is it Gold-Standart?. Reveista Médica do HC-UFPR, 2014; 1(2): 71-74.

4. BARBOSA KBF, et al. Oxidative stress: Concept. implications and modulating factors, 2010; 23(4): 629-643.

5. BOHLES $\mathrm{H}$, et al. Inadequate iron availability as a possible cause of low serum carnitine concentrations in patients with phenylketonuria. European Journal of Pediatrics, 1990; 6: 282-286.

6. CASTILLO M, et al. Inhibition of Brain and Liver 3-hydroxy-3-Methylglutaryl-CoA Reductase and Mevalonate-5Pyrophosphate Decarboxylase in Experimental Hyperphenylalaninemia, 1988; 13(6): 551-555.

7. DEON M, et al. Urinary biomarkers of oxidative stress and plasmatic inflammatory profile in phenylketonuric treated patients. International Journal of Developmental Neuroscience, 2015; 47: 259-265.

8. DUREBEX CV, et al. Hyperphenylalaninemia Correlated with Global Decrease of Antioxidant Genes Expression in White Blood Cells of Adult Patients with Phenylketonuria, 2017: 73-83.

9. EKIN S, et al. Assessment of antioxidant enzymes, total sialic acid, lipid bound sialic acid, vitamins and selected amino acids in children with phenylketonuria. Pediatric Research, 2018; 84(6): 821-828. 
10. EICHINGER A, et al. Secondary BH4 Deficiency Links Protein Homeostasis to Regulation of Phenylalanine Metabolism, 2018; 27(10): 1732-1742.

11. GARETH SA, et al. The biophysics of superoxide dismutase-1 and amyotrophic lateral sclerosis, 2019; 52(12): 1-39.

12. GASSIÓ R, et al. Cognitive Functions and the Antioxidant System in Phenylketonuric Patients. Neuropsychology, 2008; 22(4): 426-431.

13. GLORIEUX C; CALDERON PB, Catalase, a remarkable enzyme: targeting the oldest antioxidant enzyme to find a new cancer treatment approach, 2017; 398(10): 1095-1108.

14. HAGEN MEK, Experimental hyperphenylalaninemia provokes oxidative stress in rat brain. Biochimica et Biophysica Acta, 2002; 1586(3): 344-352.

15. HALLIWELL B, Oxidative stress and neurodegeneration: where are we now? Journal of Neurochemistry, 2006; $97(6)$ : 1634-1658.

16. HARGREAVES IP, et al. Coenzyme Q10 in Phenylketonuria and mevalonic aciduria, 2007; 7: 175-180.

17. JOCHUM F, et al. Is theke any health risk of low dietary selenium supply in PKU-children? Nutrition Research, 1999; 19(3): 349-360.

18. KESHAVARZI $F$, et al. Serum ischemia modified albumin is a possible new marker of oxidative stress in phenylketonuria. Metabolic Brain Disease, 2017; 33(3): 675-680.

19. KUMRU B, et al. Effect of Blood Phenylalanine Levels on Oxidative Stress in Classical Phenylketonuric Patients. Cellular and Molecular Neurobiology, 2018; 38(5): 1033-1038.

20. KUMRU B, et al. Studying the effect of large neutral amino acid supplements on oxidative stress in phenylketonuric patients. Journal of Pediatric Endocrinology and Metabolism, 2019; 32(3): 269-274.

21. LIBERATI A, et al. The PRISMA Statement for reporting Systematic Reviews and Meta-Analyses os Studies That Evaluate Health Care Interventions: Explanation and Elaboration. Plos medicine, 2009; 6(7): 1-28.

22. MIKOLUC B, et al. Impact of Lipophilic Antioxidants and Level of Antibodies Against Oxidized Low-Density Lipoprotein in Polish Children with Phenylketonuria. Antioxidants \& Redox Signaling, 2011; 16(2): 179-182.

23. MOHER D, et al. Principais itens para relatar Revisões sistemáticas e Meta-análises: A recomendação PRISMA. Epidemiol. Serv. Saúde, 2015; 24(2): 335-342.

24. NETO EV, et al. Quality Of life and adherence to treatment in early-treated Brazilian phenylketonuria pediatric patiens, 2018; 51(2): 1-10.

25. PEKALA J, et al. L-carnitine- Metabolic Functions and Meaning in Humans Life, 2011; 12(7): 667-678.

26. PREISSLER T, et al. Phenylalanine induces oxidative stress and decreases the viability of rat astrocytes: possible relevance for the pathophysiology of neurodegeneration in phenylketonuria. Metabolic Brain Disease, 2015; 31(3): 529-537.

27. REILLY C, et al. Trace element nutrition status and dietary intake of children with phenylketonuria. American Journal of Clinical Nutrition, 1990; 52(1): 159-165.

28. ROSA RRPA, Phenylketonuria: A review of Literature, 2014; 11(4): 27-47.

29. SCHULPIS $\mathrm{KH}$, et al. Serum carnitine level in phenylketonuric children under dietary control in Greece. Acta Paediatrica Scandinavica, 1990; 79(10): 930-934.

30. SCHULPIS $\mathrm{KH}$, et al. Low total antioxidant status is implicated with high 8-hydroxy-2- deoxyguanosine serum concentrations in phenylketonuria. Clinical Biochemistry, 2004; 38(3): 239-242.

31. SIERRA C, et al. Antioxidant status in hyperphenylalaninemia. Clinica Chimica Acta, 1998; 276(1): 1-9.

32. SITTA A, et al. L-carnitine blood levels and oxidative stress in treated phenylketonuric patients. Cellular and Molecular Neurobiology, 2009; 29(2): 211-218.

33. SITTA A, et al. Evidence that I-carnitine and selenium supplementation reduces oxidative stress in phenylketonuric patients. Cellular and Molecular Neurobiology, 2011; 31(3): 429-436.

34. VAN BAKEL MME, et al. Antioxidant and thyroid hormone status in selenium-deficient phenylketonuric and hyperphenylalaninemic patients. American Journal of Clinical Nutrition, 2000; 72(4): 976-981.

35. VILASECA MA, et al. Controlled diet in phenylketonuria may cause serum carnitine deficiency. Journal of Inherited Metabolic Disease, 1993; 16(1): 101-104.

36. WANG N, et al. Supplementation of Micronutrient Selenium in Metabolic Diseases: Its Role as an Antioxidant, 2017: $1-13$.

37. WANG ZY, et al. L-carnitine and heart disease. Life Sciences, 2018: 194:88-97.

38. WEIGEL C, et al. Carnitine status in early-treated children, adolescents and young adults with phenylketonuria on low phenylalanine diets. Annals of Nutrition and Metabolism, 2008; 53(2): 91-95.

39. WILKE BC, et al. Selenium, glutathione peroxidase (GSH-Px) and lipid peroxidation products before and after selenium supplementation. Clinica Chimica Acta, 1992; 207 (1): 137-142.

40. ZALEWSKA-ZIOB, et al. Activity of Antioxidant Enzymes in the Tumor and Adjacent Noncancerous Tissues of nonsmall-cell Lung Cancer, 2019: 1-9. 